\section{PROMOÇÃO DA TUTELA COLETIVA NO ESTADO DO TOCANTINS: ANÁLISE DA ATUAÇÃO DO MINISTÉRIO PÚBLICO E DEFENSORIA PUBLICA DO ESTADO}

\author{
PROMOTION OF COLLECTIVE REDRESS IN THE STATE OF \\ TOCANTINS: ANALYSIS OF THE PERFORMANCE OF THE \\ PUBLIC MINISTRY AND STATE PUBLIC DEFENDER
}

Paula Guimarães Dangelo ${ }^{1}$ Sérgio Pereira Lorentino²

\title{
RESUMO
}

O presente artigo tem como objetivo analisar a atuação do Ministério Público e Defensoria Pública do estado do Tocantins na promoção da tutela coletiva consumerista no ano de 2018. Foram utilizados dados do relatório Justiça em Números, do Sistema Nacional de Informações de Defesa do Consumidor e relatórios obtidos pelos próprios órgãos. Foi realizado um comparativo entre o número de ações individuais e coletivas ajuizadas naquele ano e os resultados foram inseridos em uma tabela, para enfim concluir que o número de ações individuais consumeristas cresce todos os anos, abarrotando o Judiciário de causas semelhantes que poderiam ser resolvidas de forma coletiva através da Ação Civil Pública. Este instrumento possibilita o desafogamento judicial e garante, de forma eficaz e ampla, o acesso à justiça.

PALAVRAS-CHAVE: Ação Civil Pública; Tutela Coletiva; Ministério Público; Defensoria Pública; Direito do Consumidor.

\footnotetext{
1 Graduada em Direito pela Universidade Federal do Tocantins. Email: pauladangelo97@gmail.com, ORCID: https://orcid.org/0000-0002-7661-3984.Contato: (63) 981265598

2 Doutor em Direito Privado pela PUC Minas, mestre em Prestação Jurisdiconal e Direitos Humanos pela Universidade Federal do Tocantins, professor adjunto do curso de direito da UFT, advogado e consultor. E-mail: sergiolorentino@uft.edu.br; ORCID: https://orcid.org/0000-0002-4114-4591 Universidade Federal do Tocantins. Qd. 109 Norte Av Ns 15 (Alcno 14 Campus Universitario S/N), Palmas · (63) 32328012.CEP 77001090. Palmas - Tocantins
} 


\begin{abstract}
This article aims to analyze the performance of the Public Ministry and Public Defender of the State of Tocantins in promoting collective consumer protection in 2018. It was collected data from the Justice in Numbers report, from the National Consumer Protection Information System and other reports. A comparison was made between the number of individual and collective actions filed that year and the results were inserted in a table, to conclude that the number of individual consumer actions grows every year, filling the Judiciary with similar causes that could be resolved promptly and collectively through Public Civil Action. This instrument enables judicial relief and guarantees access to justice effectively and comprehensively.
\end{abstract}

KEYWORDS: Public Civil Action; Collective Guardianship; Public ministry; Public defense; Consumer Law.

\title{
1 INTRODUÇÃO
}

A relação de consumo entre fornecedores e consumidores é interdependente, regida por códigos e contratos. Na cadeia de produção e circulação de mercadorias o consumidor é a parte "frágil" da relação, por isso precisa de maior proteção normativa. Porém, com a massificação da produção e do consumo a proteção aos direitos de quem adquire bens impactou o Poder Judiciário, locus de ações individuais. Essa situação fez com que o acesso à justiça se tornasse ainda mais lento, ineficiente e onerosa.

O Código de Defesa do Consumidor (CDC) possui uma preocupação especial com a proteção coletiva. A lei 8.078/90 trouxe a definição dos direitos difusos, coletivos e individuais homogêneos que permite a tutela mediante Ação Coletiva e Ação Civil Pública (Lei n. 7.347/85), pelo Ministério Público e Defensoria Pública.

Este artigo propõe analisar a atuação do Ministério Público e Defensoria pública do estado do Tocantins na defesa dos seus consumidores. Para isso, faremos a comparação entre as ações coletivas e as de ações individuais que foram ajuizadas e tramitaram no ano de 2018.

No Primeiro tópico é apresentado dados quantitativos das reclamações consumeristas, utilizando o registro do Conselho Nacional de Justiça (CNJ) e o 
Sistema Nacional de Informação de Defesa do Consumidor (SINDEC). O objetivo é colocar em relevância os reclames em nível nacional para, em seguida, recortar a parte específica ao estado do Tocantins.

No segundo tópico, faz-se o comparativo entre tutela individual e tutela coletiva em ações de consumo. Enfatiza-se neste tópico o tratamento jurídico processual e sua eficácia. Nos tópicos finais é apresentado o histórico da legitimidade garantida ao Ministério Público e Defensoria Pública, para, posteriormente identificar como é utilizada a Ação Civil Pública dentro do estado do Tocantins, através da documentação oficial recebida pelos próprios órgãos.

A análise destes dados será relevante para discutir a importância da atividade jurisdicional coletiva como forma de proteção aos consumidores. A Ação Civil Pública é o principal instrumento para minimizar o estado de hipossuficiência do consumidor.

\section{PANORAMA ESTATÍSTICO DAS RECLAMAÇÕES CONSUMERISTAS}

Desde 2004 o Departamento de Pesquisas Judiciárias do Conselho Nacional de Justiça (CNJ) realiza e publica o Justiça em números, no qual diagnostica o número de ações judicializadas, os assuntos mais recorrentes nos processos e os problemas estruturais e conjunturais dos tribunais brasileiros. Este relatório é a principal fonte de estatísticas oficiais do Poder Judiciário.

No relatório analítico de 2019 (ano base 2018) consta uma tabela com assuntos mais recorrentes deste ano, no Brasil. Na Justiça Estadual, registrou-se 1.554 .376 de ações consumeristas que correspondem a $3,74 \%$ do total das ações ajuizadas em 2018, como pode- se observar na Tabela 1. 
Tabela 1 - Justiça estadual

\begin{tabular}{llc}
\hline ÁREA & ASSUNTO & $\begin{array}{l}\text { No } \\
\text { RECLAMAÇÕES }\end{array}$ \\
\hline DIREITO CIVIL & Obrigações/Espécies de Contratos & $1.582 .067(3,81 \%)$ \\
DIREITO DO & Responsabilidade do Fornecedor/Indenização por & Dano1.554.376 (3,74\%) \\
CONSUMIDOR & Moral & $860.228(2,07 \%)$ \\
DIREITO CIVIL & Família/Alimentos & $789.071(1,90 \%)$ \\
DIREITO CIVIL & Responsabilidade Civil/Indenização por Dano Moral & $781.192(1,88 \%)$ \\
DIREITO CIVIL & Obrigações/Espécies de Títulos de Crédito &
\end{tabular}

Fonte: Elaboração própria com dados do Conselho Nacional de Justiça (2018)

Já nos Juizados Especiais ${ }^{3}$, o direito do consumidor ficou em primeiro no número de ações. Foram contabilizados 937.798, 12,4\% de processos sobre causas de responsabilidade do fornecedor e indenização por danos morais, como visto a seguir.

Tabela 2 - Juizados Especiais

\begin{tabular}{|c|c|c|}
\hline ÁREA & ASSUNTO & $\begin{array}{l}\text { № } \\
\text { RECLAMAÇÕES }\end{array}$ \\
\hline DIREITO DO CONSUMIDOR & $\begin{array}{l}\text { Responsabilidade do Fornecedor/Indenizaçã } \\
\text { por } \\
\text { Dano Moral }\end{array}$ & $0937.798(12,41 \%)$ \\
\hline DIREITO CIVIL & $\begin{array}{l}\text { Responsabilidade Civil/Indenização por Dano } \\
\text { Moral }\end{array}$ & $382.059(5,06 \%)$ \\
\hline DIREITO CIVIL & Obrigações/Espécies de Contratos & $294.693(3,90 \%)$ \\
\hline $\begin{array}{l}\text { DIREITO PROCESSUAL CIVIL } \\
\text { E DO TRABALHO }\end{array}$ & $\begin{array}{l}\text { Liquidação/ Cumprimento/ Execução/Obrigaçã } \\
\text { de } \\
\text { Fazer/ Não Fazer }\end{array}$ & $0265.719(3,52 \%)$ \\
\hline DIREITO CIVIL & Obrigações/Espécies de Títulos de Crédito & $255.448(3,38 \%)$ \\
\hline
\end{tabular}

Fonte: Elaboração própria com dados do Conselho Nacional de Justiça (2018).

\footnotetext{
${ }^{3}$ Os juizados especiais têm competência para a conciliação, o processamento, o julgamento e a execução das causas cíveis de menor complexidade (causas cujo valor não exceda a quarenta vezes o salário-mínimo.
} 
O Sistema Nacional de Informação de Defesa do Consumidor (SINDEC) foi criado para registrar as reclamações dos consumidores que recorriam ao Programa de Proteção e Defesa do Consumidor (PROCON) à medida que estes iam sendo implantados nos estados da Federação. Em 2004² foram registrados 9.187 atendimentos nos PROCONS ativos até aquele momento. Em 2018 o número de atendimentos foi para 2.274.295, desses números $26,69 \%$ eram sobre cobranças abusivas (SINDEC, 2018).

No estado do Tocantins, no ano de 2018, foram contabilizadas 40.416 (quarenta mil, quatrocentos e dezesseis) reclamações na área de direito do consumidor (SINDEC, 2018). As empresas com maior número de atendimentos no PROCON são as de telefonia celular/fixo, Oi Fixo, Claro, Vivo; os bancos públicos e privados, Bradesco e Caixa Econômica, e as empresas concessionárias de energia e saneamento, Saneatins e Energisa como observa-se na Tabela 3.

Tabela 3 - Empresas mais reclamadas

EMPRESA

OI FIXO/CELULAR

CLARO/EMBRATEL/NET

COMPANHIA DE SANEAMENTO DO TOCANITNS- SANEATINS

COMPANHIA DE ENERGIA ELETRICA DO ESTDO DO TOCANTINS- CELTINS 2.474

BRADESCO

VIVO/TELEFONIA/GVT

CAIXA ECONOMICA FEDERAL

CASAS BAHIA/ PONTO FRIO/ CNOVA/EXTRA/PAO DE AÇUCAR

ITAÚ

BMG

TIM/INTELIG

PANAMERICANO

BANCO DO BRASIL

LOJAS NOSSO LAR

SKY

Fonte: Elaboração própria com dados de Sindec (2018).
TOTAL DE

ATENDIMENTOS

4.499

2.812

2.786

2.019

1.447

1.106

1.023

895

865

838

773

754

703

624

$\mathrm{Na}$ Tabela 4 é possível visualizar quais foram os problemas levados ao PROCON naquele ano. 
Tabela 4 - Problemas mais reclamados

\begin{tabular}{lcc} 
PROBLEMA & QUANTIDADE & $\%$ \\
$\begin{array}{l}\text { SAC - Resolução +A:Kde demandas (ausência de resposta, excesso de8398 } \\
\text { prazo, não suspensão, imediata da cobrança) }\end{array}$ & $20,78 \%$ \\
Cobrança indevida/abusiva & 8203 & $20,30 \%$ \\
Dúvida sobre cobrança/valor/reajuste/contrato/orçamento & 3022 & $7,48 \%$ \\
$\begin{array}{l}\text { Contrato (não cumprimento, alteração, transferência, } \\
\text { rescisão etc.) }\end{array}$ & $5,90 \%$ \\
Produto com vício & 1709 & $4,23 \%$ \\
Contrato - Rescisão/alteração unilateral & 1285 & $3,18 \%$ \\
Não entrega/demora na entrega do produto & 1279 & $3,16 \%$ \\
Demais problemas & 6897 & $17,07 \%$ \\
\hline
\end{tabular}

Fonte: Elaboração própria com dados de Sindec (2018).

Como pode-se observar, $20,78 \%$ dos problemas são sobre os SACs das empresas que não conseguem resolver as situações internamente e os consumidores são obrigados a recorrer ao Procon. Em segundo lugar com 20,30\% das reclamações são sobre cobranças indevidas ou abusivas, ou seja, 8 mil consumidores que sofreram violações de direitos.

Inicialmente foi tentado acesso ao banco de dados do E-PROC (sistema eletrônico de ajuizamento de demandas do tribunal de justiça do Tocantins) para que pudéssemos identificar o número de ações ajuizadas contra as empresas citadas no SINDEC (Tabela 1). Foi enviado um ofício ao setor responsável pelo sistema, mas não foi possível receber as informações.

Mesmo assim, é possível dizer que, ainda que o Procon seja um meio alternativo e importante para resolução desses conflitos, nem todas as reclamações conseguem ser resolvidas pelo órgão, sendo necessário levá-las ao Judiciário. Isso significa que a maioria dos processos individuais existentes hoje na justiça brasileira são sobre assuntos semelhantes que poderiam ser juntados em uma única Ação Coletiva. 


\section{A AÇÃo COLETIVA COMO ALTERNATIVA À TUTELA INDIVIDUAL}

O Código de Processo Civil de 2015 ainda que importante para o avanço da proteção dos direitos coletivos não é um código eficaz para tratar de ações relacionadas ao consumidor, isso porque a forma como se tutela direitos privados não pode ser a mesma que se trata um direito massificado proveniente de atos de consumo intrínsecos do indivíduo.

Os contratos de consumo não recebem o tratamento legislativo necessário as especificações da relação jurídica fornecedor $x$ consumidor. Diferente dos contratos eventuais, o contrato de consumo é inevitável, não há liberdade de escolha. 0 consumidor é dependente dos produtos e serviços que somente os fornecedores podem oferecer, é esse ponto que caracteriza a hipossuficiência econômica dentro da relação jurídica. Sobre isso Enzo Roppo (2009) discute uma das partes se aproveitar de sua superioridade económica - e por isso do seu superior poder contratual - para impor unilateralmente à outra cláusulas que estabelecem derrogações e desvios ao esquema legal típico, destinadas, exclusivamente, a assegurar ao contraente "forte" vantagem e lucros e a atribuir ao contrate "débil" encargos e desvios que este último é constrangido a suportar, justamente por efeito da sua inferior posição económico-social (ROPPO, 2009 apud LORENTINO, 2017, p. 32).

$\mathrm{O}$ ordenamento jurídico deve se adequar as mudanças estruturais, sociais e culturais do país em que ele se insere, por isso é que os contratos de consumo devem receber tratamento jurídico adequado e principalmente eficaz. A tutela coletiva tem capacidade de potencializar o alcance da tutela contratual de consumo e promover a redução das demandas individuais.

Como as ações coletivas não são preferidas e nem estimuladas, os consumidores continuam a recorrer à tutela jurisdicional individualmente causando o abarrotamento de processos, demora na resolução destes e alto custo. Em consequência disso o sistema judiciário é descredibilizado e outros consumidores acabam por desistir das ações, formando um "universo gigantesco de demandas consumeristas reprimidas". 
Há ainda aquelas violações de direitos praticados pelo fornecedor que passam desapercebidas pelo consumidor, ou, não possui relevância patrimonial suficiente para movimentar a justiça. Por exemplo, pequenos descontos de um real debitados na conta corrente do cliente todo mês. Conforme argumenta Aluísio Mendes (2010), acerca dos pequenos dados se considerados separadamente, em termos econômicos, de pequena monta, fazendo com que, na relação custo-benefício, o ajuizamento de ações individuais seja desestimulante, e, na prática, quase que inexistente, demonstrando assim, a fragilidade e as deficiências em relação ao acesso à justiça. A eventual falta ou deficiência dos instrumentos processuais adequados para os chamados danos de "bagatela", que, considerados globalmente, possuem geralmente enorme relevância social e econômica, estipula a repetição e perpetuação de práticas ilegais e lesivas. (MENDES, 2010, p. 63-64 apud LORENTINO, 2017, p. 164).

Aqueles que mesmo assim decidem entrar com um processo, ao final deste recebem uma reparação, muitas vezes de valor já tabelado no caso de danos morais e a empresa segue em vantagem. A tática dos fornecedores de massa (bancos, financeiras, operadores de telecomunicações de cartão de crédito etc.) é o da "análise puramente econômica de seus atos" (LORENTINO, 2017, p. 166), não há consequência maior do que essas já esperadas.

Diferente da ação individual, que tem efeito inter partes, a ação coletiva possui efeito erga omnes, significa que os efeitos alcançam os indivíduos fora da relação jurídica e ainda é um mecanismo de controle social, sobre isso Sérgio Shimura (2006) ressalta que com essa ação, a sociedade pode, através das associações de classe e das fundações privadas, exigir do Estado a implementação de políticas públicas, relacionadas, por exemplo, ao consumidor. As decisões proferidas na Ação civil pública têm o poder de gerar uma mudança de conduta, uma vez que se trata de anseios da coletividade e não apenas de um indivíduo.

Os direitos que a Ação Civil Pública protege são os direitos difusos, coletivos e individuais homogêneos. O direito difuso é definido no Código do Consumidor (CDC) como aqueles "de que sejam titulares pessoas indeterminadas e ligadas por circunstâncias de fato". Essa circunstância de fato, normalmente diz respeito a violação 
de princípios constitucionais ou valores sociais de grande repercussão. Por exemplo, um elenco de pessoas atingidas pela contaminação da água de um rio ou destinatários de propaganda enganosa.

O direito coletivo é a junção do direito individual do sujeito inserido em um grupo ou classe que se transforma em um direito da categoria. Quando um grupo luta por melhores condições de segurança no trabalho, são todos os trabalhadores, como categoria, que disso poderão beneficiar-se, independentemente de sua precedente adesão à entidade representativa (MANCUSO, 1994). Já os direitos individuais homogêneos são aqueles que decorrem de origem comum, por exemplo quando um veículo apresenta defeito, lesando vários consumidores, mas que não há relação jurídica e não podem ser determinados formalmente.

A tutela destes tipos de direitos não pode depender apenas da ação dos próprios interessados. Os indivíduos isolados estão em uma situação de desvantagem em relação ao violador dos direitos. Para superar tais limitações da "fórmula processual individualista", segundo Cappelletti e Bryant (2002), seria atribuir a uma instituição estatal, o Ministério Público, o papel de tutelar os interesses difusos da sociedade que até então encontravam-se desprotegidos. Assim, a tutela coletiva de direitos veio em resposta aos novos aspectos da sociedade a fim de garantir o efetivo acesso à justiça.

A Ação Civil Pública, portanto, implica uma tutela mais ampla e alivia o sistema judiciário. Recorrer a tutela jurisdicional não é tarefa que se faça sem o devido esforço por parte do consumidor, por isso, resolveria, também, o problema das demandas reprimidas possibilitando a reparação danos econômicos que não seriam ajuizados pelo consumidor individualmente.

\section{LEGITIMIDADE CONFERIDA AO MINISTÉRIO PÚBLICO E DEFENSORIA PÚBLICA}

A Ação Civil Pública, diferente da Ação Popular, só poderá ser proposta por entes públicos e associações privadas que preencham os requisitos da lei. O art. $5^{\circ}$ da 
Lei $n .{ }^{\circ} 7.347 / 85$ traz 0 rol taxativo das entidades legítimas para propor a ação civil pública:

I - o Ministério Público; II - A Defensoria Pública;

II- a União, os Estados, o Distrito Federal e os Municípios;

III- autarquias, empresas públicas, fundações e sociedades de economia mista;

IV- associações que, concomitantemente, estejam constituídas há pelo menos 1 (um) ano nos termos da lei civil (BRASIL, 1985, n.p).

A Constituição de 1988 traz que uma das funções do Ministério Público é promover o inquérito civil e a ação civil pública, para a proteção do patrimônio público e social, do meio ambiente e de outros interesses difusos e coletivos (art. 129, III, CF/88) ${ }^{3}$ já que é uma instituição de fiscalização para salvaguardar os direitos da sociedade. No entanto, é proibido constitucionalmente de atuar na defesa de direitos patrimoniais individuais (não-homogêneos) já que ao Parquet, em regra, foi confiada tão-somente a defesa dos interesses coletivos e individuais indisponíveis (CF., art. 127 e 129, III). Sobre isso, Ana Lúcia Amaral, procuradora da República em São Paulo discorre que

Ao estabelecer o constituinte, como função institucional do Ministério Público, a promoção da ação civil pública para a defesa coletiva dos direitos, quer individuais quer coletivos, demonstrou sensibilidade, e estar atento à situação de marginalidade em que vive parte expressiva da população, flagrantemente hipossuficiente face os chamados Poderes públicos. Por não se encontrar, ainda, a sociedade civil devidamente organizada, de sorte a defender, através de associações e outros entes, os seus interesses, no atendimento de suas necessidades, incumbe no momento ao Ministério Público, precipuamente por força de sua função institucional, trazer ao Poder Judiciário as grandes questões, já que os outros Poderes do Estado, por sua própria natureza, não poderiam dirimi-las, além do que, em muitas oportunidades, atuam contra os direitos fundamentais dos cidadãos (AMARAL, 1992 apud ARANTES, 1999 p. 96).

Por força da legitimidade ativa, o dever de propor a ação civil pública é direito indisponível do MP, essa competência deve ser exercitada. Fala-se em princípio da obrigatoriedade quando se quer referir ao dever que tem o órgão do Ministério Público de promover a ação pública, dela não podendo desistir. Não se admite que o Ministério Público, identificando uma hipótese em que deva agir, se recuse a fazê-lo, porém não 
se trata de um dever cego, tem liberdade para identificar ou não a hipótese de atuação. Se o MP identifica a existência da lesão a um direito é dever do parquet propor a ação. Entretanto, há os casos em que a lei lhe concede discricionariedade para agir de acordo com os critérios de oportunidade e conveniência e interesse público. A legitimidade constitucional é disjuntiva e concorrente (FIGUEIREDO, 1997).

Foi a Constituição Federal que alterou a Lei n.ำ 7.347/85 e acrescentou no rol dos legitimados a Defensoria Pública. Trata-se de uma alteração importante para a tutela coletiva, visto que a Defensoria é instituição permanente essencial à função jurisdicional do Estado, protegendo os direitos individuais coletivos de forma integral e gratuita aos necessitados (art, 5ำ, LXXIV, CF/88). O grande problema foi estabelecer em quais tipos de processos a defensoria seria legitima a propor a ACP.

Tendo em vista que a Defensoria Pública tem como principal objetivo a proteção dos necessitados, o STJ (RESP № 1.192.577) decidiu em 2014 que

A Defensoria Pública tem pertinência subjetiva para ajuizar ações coletivas em defesa de interesses difusos, coletivos e individuais homogêneos, sendo que no tocante aos difusos, sua legitimidade será ampla (...) no entanto, em se tratando de interesses coletivos em sentido estrito ou individuais homogêneos diante de grupos determinados de lesados, a legitimação deverá ser restrita às pessoas notadamente necessitadas (BRASIL, 2015a, p. 4, grifo do autor).

Acontece que, em se tratando de consumidores, todos os indivíduos, independente de classe social e poder monetário, estão em situação de hipossuficiência na condição de dependência daquele produto ou serviço, portanto a decisão reduziu a área de atuação da Defensoria. Em contrapartida, o STF (ADI 3943) em 2015 reconheceu que a comprovação prévia de pobreza não deveria condicionar a atuação da Defensoria Pública e reconheceu sua legitimidade para a tutela coletiva (BRASIL, 2015).

No caput do art. 5o da Lei $n .{ }^{0} 7.347 / 85$ diz que o Ministério Público e outros legitimados poderão propor a ação principal e a ação cautelar, compreendido com um dever de agir, mas não obriga aos legitimados a propositura da ação, de acordo com o art. 9o "se o órgão do Ministério Público, esgotadas todas as diligências, se convencer 
da inexistência de fundamento para a propositura da ação civil, promoverá o arquivamento dos autos do inquérito civil ou das peças informativas, fazendo-o fundamentadamente". Mas, presentes os pressupostos do exercício da Ação Civil Pública cabem ao MP não apenas o direito, mas o dever indisponível de propô-la.

O Código de Processo Civil de 2015 apesar das ressalvas comentadas anteriormente, trouxe artigos importantes, por exemplo, art. 139 quando diz que:

Art. 139. O juiz dirigirá o processo conforme as disposições deste código, incumbindo-lhe:

$[\ldots]$

X- quando se deparar com diversas demandas individuais repetitivas, oficiar o Ministério Público, a Defensoria Pública e, na medida do possível, outros legitimados a que se referem o art. 50 da Lei 7.347, de 24 de julho de 1985, e o art. 82 da Lei 8.078, de 11 de setembro de 1990, para, se for o caso, promover a propositura da ação coletiva respectiva. (BRASIL, 2015)

Dessa forma, autorizando a jurisdição a adotar as providências do inciso $\mathrm{X}$ quando se depararem com demandas repetitivas. E ainda, previu a participação do Ministério Público e da Defensoria Pública em seu art. 176 e art. 185 do CPC/15:

Art. 176. O Ministério Público atuará na defesa da ordem jurídica, do regime democrático e dos interesses e direitos sociais e individuais indisponíveis.

$[\ldots]$

Art. 185. A Defensoria Pública exercerá a orientação jurídica, a promoção dos direitos humanos e a defesa dos direitos individuais e coletivos dos necessitados, em todos os graus, de forma integral e gratuita (BRASIL, 2015)

A legitimidade conferida deixa livre os órgãos e os demais integrantes do sistema de justiça para a aplicação da tutela coletiva quando se achar necessário mas, até que ponto essa liberdade de atuação tem servido aos consumidores e ao desenvolvimento das Ações Coletivas, visto que não há um direcionamento para pautas preferenciais. 


\section{A SUB-UTILIZAÇÃO DA TUTELA COLETIVA NO ESTADO DO TOCANTINS}

Para desenvolver esse artigo foi enviado um ofício a Defensoria Pública do Estado do Tocantins e para o Ministério Público do estado solicitando que fosse disponibilizado o número de Ações Civis Públicas que as instituições propuseram no ano de 2018.

O Ministério Público respondeu a solicitação e enviou o número das três ACP que foram ajuizadas naquele ano. A primeira delas foi uma ação direcionada a BRK Ambiental acerca da taxa de esgoto do município de Palmas que consistente em $80 \%$ (oitenta por cento) do valor cobrado pelo fornecimento de água, que ao final foi indeferida.

A segunda também tem como polo passivo a BRK Ambiental e a ATR - Agência Tocantinense de Regulação com objetivo de impedir que a empresa cobre dos consumidores taxas ilegais, como de religamento e suspensão dos serviços, como explica trecho retirado da inicial do processo "obter o reconhecimento da ilegalidade das cobranças das taxas referentes ao pedido de suspensão e religamento dos serviços de fornecimento de água e esgoto, bem como da "tarifa mínima" que é aplicada após o corte do fornecimento destes serviços, devendo a concessionária BRK Ambiental ser condenada a cessar as cobranças indevidas e a indenizar os consumidores lesados". $O$ processo, no entanto, continua em andamento.

A última ação promovida pelo Ministério Público, em 2018, tem como polo passivo o Estado do Tocantins que apurou durante Inquérito Civil indícios de lesão aos direitos dos Consumidores usuários do serviço de emplacamento de motocicletas e veículos automotores no Estado do Tocantins, segundo a investigação a ASPLATO Associação de Fabricantes de Placas de Veículos Automotores do Estado do Tocantins, foi criada especificamente com o intuito de manipular e controlar os preços resultantes da fabricação e comercialização de placas veiculares em todo Estado do Tocantins, tendo a conivência e a autorização do Departamento Estadual de Trânsito, através das Portarias expedidas por aquele órgão. O processo ainda corre na justiça. 
Por mais que essas ações sejam sobre assuntos importantes para o consumidor tocantinense, não é o assunto principal dos processos que lotam o Poder Judiciário do estado. Como visto no primeiro tópico a maioria dos casos que vão para o PROCON são sobre cobranças abusivas e nada foi feito quanto a isso em termos de ação coletiva.

Como vimos no primeiro tópico as informações existem. O Ministério Público, órgão criado para a defesa da ordem pública, não está atuando como deveria. $O$ fato de existir tantas reclamações de uma mesma empresa seria justificativa plausível par a instauração de um Inquérito civil para averiguar situações de violação de direitos.

Através do ofício enviado à Defensoria Pública foi possível, também, ter acesso aos processos coletivos impetrados pela instituição. O Dr. Daniel Silva Gezoni, coordenador do NUDECON (Núcleo de Defesa do Consumidor) encaminhou o ofício as Comarcas do Tocantins. Responderam ao pedido, a comarca de Palmas, Tocantinópolis, Araguaína, Gurupi, Itaguatins e Dianópolis. Concluindo que nenhuma das comarcas citadas impetraram Ação Civil Pública no ano de 2018, e ainda que Tocantinópolis promoveu duas ACP no ano de 2014 e 2015 e que Gurupi, desde a criação do órgão só impetrou uma ACP em 2017.

A Defensoria Pública é uma Instituição extremamente importante para a população. Tem como objetivo buscar o reequilíbrio social, foi criada para corrigir as violações de direitos sofridos pela população carente e ter sido inseria no rol dos legitimados para a propositura da Ação Civil Pública foi um marco e retirou o monopólio do Ministério Público. Diferente do Ministério Público a Defensoria é legitima para atuar na defesa dos direitos individuais homogêneos também. Infelizmente, no Tocantins, a DPE não está exercitando essa legitimidade conquistada, fato extremamente prejudicial ao consumidor.

Tratando-se de uma Ação Pública, por conta do objeto social tutelado, a defesa dos interesses deve ser realizada pelos órgãos públicos competentes. Como autor, o MP defende, em nome próprio, direito alheio, caracterizando-se legitimação extraordinária de substituição processual, dessa forma para o órgão ministerial agir 
deve haver prova de interesse social relevante, direitos indisponíveis (art. 127, CF/88). Sobre isso, Hugo Mazzili assevera:

a defesa dos interesses de meros grupos determinados de pessoas (como consumidores individualmente lesados) só se pode fazer pelo Ministério Público quando isto convenha à coletividade como um todo (...); se é extraordinária a dispersão de lesados; se a questão envolve defesa da saúde ou da segurança dos consumidores; se a intervenção ministerial é necessária para assegurar o funcionamento de todo um sistema econômico, social ou jurídico. Não se tratando de hipótese semelhante, a defesa de interesses de consumidores individuais deve ser feita por meio de legitimação ordinária, ou, se por substituição processual, por outros órgãos e entidades que não o Ministério Público, sob pena de ferir-se a destinação institucional deste último (MAZZILI, 1995, p. 83).

O Ministério Público por se tratar de uma instituição ligada ao Estado, segundo Cappelletti (2009) não é capaz de assumir a defesa dos interesses difusos e coletivos. O autor afirma que eles (MP) "são amiúde sujeitos a pressão política - uma grande fraqueza, se considerarmos que os interesses difusos, frequentemente, devem ser afirmados contra entidades governamentais". A proximidade com o Estado poderia comprometer sua independência para proteger direitos que por vezes são violados pelo próprio Estado.

Por isso que a Defensoria Pública é tão importante para proteção dos direitos difusos, coletivos e individuais homogêneos. Os conflitos de massa são cercados de relevância política e são capazes de transformar conceitos jurídicos estagnados e conscientizar os produtores, fornecedores dos produtos ou serviços, a propósito, Pedro da Silva Dinamarco (2001) leciona que:

Mas sua maior importância talvez realmente esteja na conscientização daquele que usualmente causava danos a interesses metaindividuais. Alguns fornecedores degradadores do meio ambiente, e outras pessoas que estavam acostumadas a subestimar os direitos metaindividuais, diante da secular impunidade que cercava essas questões, passaram a temer a mera potencialidade de uma demanda judicial coletiva. Não só a demanda em concreto, na qual ele já figura como réu, mas o grande risco potencial que uma demanda coletiva pode significar para sua sobrevivência econômica (DINAMARCO, 2001, p. 45). 
Uma empresa de grande porte prefere que existam milhares de pequenos processos consumeristas, do que uma grande Ação Coletiva. Os processos individuais podem ser facilmente resolvidos em uma conciliação em que a empresa paga ao consumidor um valor irrisório de danos morais.

A dificuldade, pelo que vimos, é estabelecer as prioridades do MPE e DPE para iniciar um processo coletivo. Por isso, é necessário que essas instituições se posicionem, investiguem e interpretem um papel mais ativo na proteção do consumidor, já que é a jurisdição que irá transformar as relações de consumo, de forma que cada caso seja uma oportunidade para concretizar direitos.

[...] a satisfação do direito passa a ter importância político social na realização concreta da jurisdição, seja por fazer respeitar os comandos do Estado-Juiz, seja por fazer distribuir e circular rendas e bens de consumo, que representariam o desenvolvimento econômico necessário para impulsionar transformações sociais visadas no art. $3^{\circ}$ da Constituição Federal (PAULA, 1999, p. 147, apud LORENTINO, 2017, p. 154)

Sendo assim, a Ação Civil Pública além de garantir maior acesso à justiça é também instrumento de mudança e de transformação dentro da sociedade, principalmente na relação entre consumidor e fornecedor.

\section{CONSIDERAÇÕES FINAIS}

Podemos concluir que a Ação Civil Pública é de extrema importância para proteção dos consumidores. $O$ instrumento consegue dar visibilidade a questões consumeristas que nas pequenas ações individuais ficam reprimidas, pelas indenizações, acordos e sentenças contraditórias.

Além disso, uma ação coletiva tem capacidade de assegurar que atos lesivos utilizados pelas grandes empresas sejam impedidos de se efetivar, assim garantindo que consumidores futuros não sejam atingidos.

Mesmo assim, não é um instrumento que tem sido aproveitado pelo Ministério Público e Defensoria Pública. $O$ número de ações individuais continua a crescer 
exponencialmente todos os anos, esse fenômeno causa insegurança jurídica para os consumidores e contribui para a desmoralização do judiciário. Por isso, a necessidade da tutela coletiva capaz de viabilizar de forma mais eficaz o acesso à justiça.

Apesar das dificuldades burocráticas na obtenção dos dados relevantes à pesquisa, o objetivo foi alcançado. Possibilitou a constatação de que a Defensoria Pública e o Ministério Público promoveram pouquíssimas ou nenhuma Ação Civil Pública no ano de 2018, os órgãos não têm desempenhado seus papeis para resolver os numerosos problemas consumeristas frente as grandes empresas do estado.

Não havia, até então, uma pesquisa que averiguasse a situação da tutela coletiva no estado do Tocantins, percebe-se que apesar de ser um estado novo, ainda se encontra tímido para lidar com grandes questões que causam repercussão social, econômica e política.

Os órgãos devem colocar-se numa posição mais ativa, principalmente a Defensoria Pública que foi criada justamente para proteção dos hipossuficientes e garantir a igualdade de tratamento dentro da relação jurídica. Resta saber se essas instituições têm buscado conhecer os interesses da comunidade e se sabem reconhecer quais questões são de maior urgência.

O desenvolvimento futuro dessa pesquisa pode servir para incentivar a mudança de conduta dessas instituições, e pode ser enviada diretamente a eles com os dados e embasamento teórico necessários, além de estimular outras pesquisas acadêmicas sobre o a tutela coletiva e direito do consumidor, que tanto carece de atenção.

\section{REFERÊNCIAS}

AMARAL, Ana Lúcia. Processo civil coletivo: o acesso à Justiça no ano 2000. São Paulo: Mimeo, 1992.

ARANTES, Rogério Bastos. Direito e politica: o Ministério Publico e a defesa dos direitos coletivos. Revista brasileira de ciências sociais, v. 14, n. 39, 2009.

BASTOS, Antonio Adonias Aguiar. Situações jurídicas homogêneas: um conceito necessário para o processamento das demandas de massa. Revista de Processo, São Paulo, v. 186, p. 87- 107, ago. 2010. 
BRASIL. Lei n.o 7.347, de 24 de julho de 1985. Disciplina a ação civil pública de responsabilidade por danos [...]. Brasília: Casa Civil, 1985. Disponível em: http://www.planalto.gov.br/ccivil 03/leis/l7347orig.htm. Acesso em: 31 out. 2020.

\section{Constituição Federal de 1988. Constituição da República Federativa do Brasil. Brasília: Casa Civil, 1988. Disponível em: http://www.planalto.gov.br/ccivil 03/constituicao/constituicaocompilado.htm. Acesso em: 31 out. 2020.}

.. Lei $n$. - 8.078, de 11 de setembro de 1990. Dispõe sobre a proteção do consumidor e dá outras providências. Brasília: Casa Civil, 1990. Disponível em: http://www.planalto.gov.br/ccivil 03/leis//8078compilado.htm. Acesso em: 31 out. 2020.

.. Supremo Tribunal de Justiça. Embargos de Divergências em Resp. N.은 1.192.577 - Rio Grande do Sul. Embargante: Defensoria Pública do Estado do Rio Grande do Sul.Embargado: Sociedade Dr. Bartholomeu Tacchini - Plano de Saúde Tacchimed. Relatora:Ministra Laurita Vaz. 21 de outubro de 2015a. Lex: jurisprudência do Supremo Tribunal de Justiça, Brasília, 2015a. Disponível em: https://www.conjur.com.br/dl/defensoria-propor-acp- defesa.pdf. Acesso em: 31 out. 2020.

Supremo Tribunal Federal. Ação Direta de Inconstitucionalidade 3.943 Distrito Federal. Requerente: Associação Nacional dos Membros do Ministério Público CONAMP. Intimados: Presidente da República e Congresso Nacional. Relatora: Ministra Carmém Lúcia. 7 de maio de 2015. Lex: jurisprudência do Supremo Tribunal Federal, Brasília, 2015b. Disponível em: http://redir.stf.jus.br/paginadorpub/paginador.jsp?docTP=TP\&doclD=9058261. Acesso em: 31 out. 2020.

CALMON DE PASSOS, José Joaquim. O problema do acesso à justiça no Brasil. Revista dos Tribunais, v. 10, n. 39, p. 78-88, jul.set. 1985.

CAPPELLETTI, Mauro. $O$ acesso à justiça como programa de reformas e método de pensamento. In: MADUREIRA, Claudio Penedo. Temas de Direito Público: a importância da atuação da advocacia pública para a aplicação do direito. Revista da APES - Vol.2. Salvador: Ed. Juspodivm, 2009.

CAPPELLETTI, Mauro; BRYANT Garth. Acesso à justiça. Porto Alegre: Sergio Antonio Fabris Editor, 2002.

CNJ - CONSELHO NACIONAL DE JUSTIÇA. Justiça em Números. Brasília: CNJ, 2019. Disponível em: https://www.cnj.jus.br/wpcontent/uploads/conteudo/arquivo/2019/08/justica em numeros20190919.pdf Acesso em: 13 nov. 2020.

DINAMARCO, Cândido Rangel. A reforma do código de processo civil. São Paulo, Malheiros: 2001. 
FIGUEIREDO, Lucia Valle. Ação Civil Pública. Ação Popular. A defesa dos interesses difusos e coletivos: posição do Ministério Público. Revista de Direito Administrativo, Rio de Janeiro, n. 208, p. 35-53, 1997.

LORENTINO, Sérgio Augusto Pereira. A jurisdição e os contratos de consumo: entre o direito posto e a facticidade. Belo Horizonte: Ed. Del Rey, 2017.

MANCUSO, Rodolfo de Camargo. Interesses Difusos: conceito e legitimação para agir. São Paulo: Revista dos Tribunais, 1994.

MAZZILI, Hugo Nigri. A Defesa dos Interesses Difusos em Juízo. São Paulo: Saraiva, 1995.

PAULA, Jônatas Luiz Moreira de Paula. Uma visão crítica da jurisdição civil. LemeSP: LED - Editora de Direito Ltda, 1999.

SHIMURA, Sérgio. O papel da associação na ação civil pública. In: SHIMURA, Sérgio.Tutela Coletiva e sua efetividade. São Paulo: Método, 2006.

SINDEC - SISTEMA NACIONAL DE INFORMAÇÕES DE DEFESA DO

CONSUMIDOR. Atendimentos. Brasil, 2020. Disponível em: https://sindecnacional.mi.gov.br/report/Atendimentos Acesso em: 13 nov. 2020.

SINDEC - SISTEMA NACIONAL DE INFORMAÇÕES DE DEFESA DO

Empresas. Brasil, $2020 . \quad$ Disponível

em:

https://sindecnacional.mj.gov.br/report/Empresas. Acesso em: 13 nov. 2020. 